\section{Application of an Efficient Amperometric Glucose Sensing Electrode Based on a Bilayer Polymer Film Platform}

\author{
Hava Zekiye Kaya, ${ }^{1}$ Saniye Söylemez, ${ }^{2}$ Yasemin Arslan Udum, ${ }^{3}$ and Levent Toppare ${ }^{1,4,5,6, z}$ \\ ${ }^{I}$ The Center for Solar Energy Research and Application (GUNAM), Middle East Technical University, Ankara 06800, \\ Turkey \\ ${ }^{2}$ Department of Chemistry, Ordu University, Ordu 52200, Turkey \\ ${ }^{3}$ Technical Sciences, Vocational High School, Gazi University, 06374, Turkey \\ ${ }^{4}$ Department of Chemistry, Middle East Technical University, Ankara 06800, Turkey \\ ${ }^{5}$ Department of Biotechnology, Middle East Technical University, Ankara 06800, Turkey \\ ${ }^{6}$ Department of Polymer Science and Technology, Middle East Technical University, Ankara 06800, Turkey
}

\begin{abstract}
A new approach was developed using a combination of a conducting polymer; poly(3,4-ethylenedioxythiophene) (PEDOT) with the electrochemically produced polymer of $\mathrm{N}$-ferrocenyl-3-(1H-pyrrol-1-yl)aniline, (PFcPyBz) layer for the enzyme scaffolding resulting in excellent analytical parameters. To organize such a surface, graphite electrode was coated with a PEDOT layer and it was used as a transducer for electrochemical deposition of the polymer of a newly synthesized FcPyBz monomer. Using a PEDOT layer as the working electrode improved localization of the PFcPyBz on the transducer surface while enhancing the biosensor performance. A simple binding of glucose oxidase (GOx) as a test enzyme on this new polymeric platform was achieved using glutaraldehyde (GA) as the cross linker. The low limit of detection and high sensing sensitivity on glucose for the biosensor are estimated as $54 \mu \mathrm{M}$ and $112.2 \mu \mathrm{A} / \mathrm{mMcm}^{2}$, respectively. The surface characterizations of the modified electrodes were investigated by cyclic voltammetry (CV), attenuated total reflectance-fourier transform infrared (ATR-FTIR) spectroscopy and scanning electron microscopy (SEM) techniques. Finally, different kinds of beverages were tested for sensor reliability with high accuracy.

(c) 2018 The Electrochemical Society. [DOI: 10.1149/2.1121816jes]
\end{abstract} 63 after the invention of the Fc molecule in 1951 , scientist paid attention

A well-known disorder, diabetes mellitus occurs via an increase in glucose concentration in human blood. Since it is spreading worldwide, its careful and precise detection gained importance to reduce the threat. ${ }^{1,2}$ Mirroring the importance of the disease is the worldwide interest leading to publishing a number of articles per year. These developments have opened ways to the wide array of emerging applications in glucose biosensors. Development of the glucose oxidase based enzyme biosensors by different immobilization techniques on various kind of electrodes had been studied for several decades. ${ }^{3,4}$ Conjugated polymers (CPs) promise to advance a number of real-world technologies. Of these applications, they are particularly attractive for uses in enzyme biosensors for environmental and health monitoring. Their unique properties such as high electrical conductivity, ease of preparation and good environmental and chemical stability have motivated the use of CPs in the form of thin films for biosensors. ${ }^{5,6} \mathrm{CP}$ based biosensors bring simple, accurate, reliable and low-cost determination of various analytes and act as a very effective analytical tool in the multiple areas. This description is also supported by a number of researchers using the CPs as an immobilization architecture. ${ }^{7-10}$

PEDOT has been reported to exhibit superior stability in conductivity compared to other available polymers and this property prompted us to use the PEDOT film as a transducer in order to obtain a more stable scaffolding for the glucose sensor. Brett and co-workers developed a PEDOT/poly (methylene blue) (PMB) modified glassy carbon electrode (GCE) for a GOx-based biosensor. ${ }^{11}$ PEDOT films generated on top of PMB modified bare electrode was used to enhance the stability of PMB modified electrode. The proposed sensing architecture (GOx/PEDOT/PMB/GCE) showed better biosensor performance than the ones for GOx/GCE and GOx/PEDOT/GCE biosensors. In another work, Si reported a simple synthesis of a hybrid film by electropolymerizing 3,4-ethylenedioxythiophene (EDOT) on nanoporous gold (NPG) for applications in amperometric glucose biosensors. ${ }^{12}$ They finally concluded that the NPG/PEDOT/GOx biosensor prepared by optimum film thickness is appropriate for effective substrate diffusing. PEDOT is also used as the working electrode for glucose sensing by Ho and co-workers. ${ }^{13}$ In this work, PEDOT and ferrocene (Fc) containing polymer were used for not only reducing the working potential but also for improving the stability of the sensor. Moreover, ${ }^{\text {zE} E-m a i l: ~ h z a k p i n a r @ y a h o o . c o m ; ~ t o p p a r e @ m e t u . e d u . t r ~}$ huge number of molecules containing Fc moiety were designed and assessed for their possible use in glucose sensing applications. ${ }^{16,17}$ Electrodeposited copolymer of pyrrole and ferrocene carboxylate modified pyrrole $\mathrm{p}(\mathrm{Py}-\mathrm{FcPy}),{ }^{18}$ co-deposition of 4-(2,5-di(thiophen-2yl)-1H-pyrrol-1-yl) aniline (SNS-NH $\left.{ }_{2}\right)$ and 4-(2,5-di(thiophen-2-yl)1H-pyrrol-1-yl) amidoferrocenyldithiophosphonate (SNS-NH2-Fc) ${ }^{19}$ and copolymer of O-4-(1H-pyrrol-1-yl)-ferrocenyldithiophosphonate (TPFc) with 4-(2,5-di(thiophen-2-yl)-1H-pyrrol-1-yl)butane-1-amine (TPA $)^{20}$ are the examples of the conjugated polymer based electronmediating support materials for developing GOx immobilized electrodes. Under the light of this, this work will show a significant way to create CPs-based glucose biosensors exhibiting selective responses to a target analyte. Such approach predominantly includes functionalization of PEDOT bearing surface with newly synthesized Fc moiety containing polymer.

In this report, for the first time a PEDOT transducer was designed and a new one-pot synthesized ferrocene containing monomer was electrochemically deposited on a well-known polymer (PEDOT) surface for glucose sensing. Without the PEDOT layer it was difficult to coat $\mathrm{PFcPyBz}$ layer on the bare graphite surface. For this reason, the electrode surface is first modified with PEDOT and then coated with PFcPyBz. We described the importance and effect of CPs in biosensor construction that was highlighted in our previous works. ${ }^{21,22}$ However, need for a promising analytical devices for glucose sensing with high accuracy and sensitivity has motivated us to design a new sensing system. Designing of the new surface in this study, a highly sensitive and reliable glucose sensor was developed with the help of glucose oxidase (GOx), as a model enzyme. Detailed optimization studies, surface characterization of the polymer layers and the amperometric characterization were performed. Additionally, the testing of the biosensor was conducted using different kinds of commercial beverages.

\section{Experimental}

Chemicals and instrumentation.-All chemicals which were used for monomer synthesis and electrochemical polymerization, were purchased from Aldrich and used without further purification. Materials used for biosensor construction were also obtained from Aldrich. Glucose oxidase enzyme used in this study was (GOx, $\beta$-D-glucose: oxygen 1-oxidoreductase, EC 1.1.3.4, 17300 units/g solid) from $A$. Niger. Electrochemical polymerizations of the EDOT and the FcPyBz 


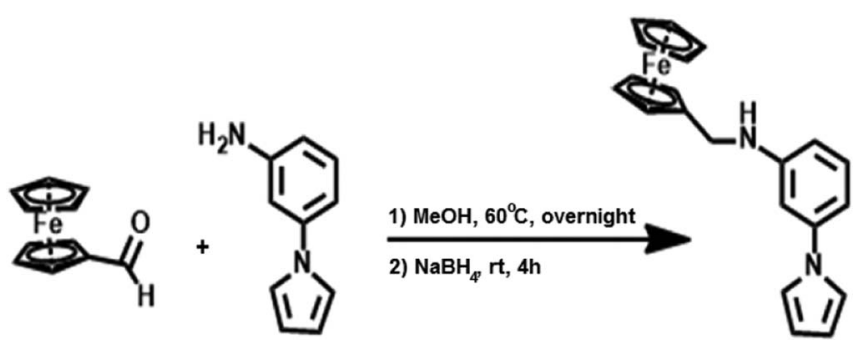

Scheme 1. Synthetic route for the ferrocene containing monomer ( $\mathrm{FcPyBz})$.

105 monomers were performed by GAMRY Reference 600 potentio106 stat/galvanostat using three electrode system containing platinum 107 counter and silver wire reference electrodes. Amperometric measure108 ments were performed using Palm Instrument (PalmSens, Houten, 109 The Netherlands) with the same electrode configuration. Graphite 110 electrodes (type RW001, $3.05 \mathrm{~mm}$ diameter and 13\% porosity) were 11 obtained from Ringsdorff Werke GmbH, Bonn, Germany. In amper12 ometric analyses, the data were given as the average of three mea13 surements and standard derivations were recorded as \pm SD. JEOL 14 JSM-6400 models SEM was used to investigate the layers of the fab115 ricated biosensor. 118 literature $^{23}$ (Scheme 1). $676.5 \mathrm{mg}(3.16 \mathrm{mmol})$ ferrocene carbox119 aldehyde and $500 \mathrm{mg}(3.16 \mathrm{mmol}) 3-(1 H$-pyrrol-1-yl)aniline were 120 dissolved in $15 \mathrm{~mL}$ methanol in a $100 \mathrm{~mL}$ round bottom flask fitted 121 with a condenser and stirred overnight at $60^{\circ} \mathrm{C}$. After the solution was 122 cooled, $177 \mathrm{mg}(4.74 \mathrm{mmol}) \mathrm{NaBH}_{4}$ were added into the solution 123 and stirred for an additional 4 hours at room temperature. Then, the 124 reaction mixture was poured into $100 \mathrm{~mL}$ of distilled water and the 125 solution was extracted using ethyl acetate (EtOAc) for several times. 126 The organic layer was dried with $\mathrm{Na}_{2} \mathrm{SO}_{4}$ and the solvent was evap127 orated under vacuum. The purification of the residue was performed 28 by column chromatography using hexane:EtOAc (3:1) as the eluent. ${ }_{29}$ Yellow crystals were obtained with a yield of $27 \% .{ }^{1} \mathrm{H}$ NMR (400 30 $\left.\mathrm{MHz}, \mathrm{CDCl}_{3}, \mathrm{ppm}\right) \delta: 7.22(\mathrm{t}, 1 \mathrm{H}), 7.08(\mathrm{~d}, 2 \mathrm{H}), 6.74(\mathrm{dd}, 1 \mathrm{H}), 6.65$ 31 (s, 1H), $6.54(\mathrm{dd}, 1 \mathrm{H}), 6.33(\mathrm{t}, 2 \mathrm{H}), 4.26(\mathrm{t}, 2 \mathrm{H}), 4.20(\mathrm{~s}, 5 \mathrm{H}), 4.17(\mathrm{t}$, $\left.{ }_{32} 2 \mathrm{H}\right), 4.04(\mathrm{~s}, 1 \mathrm{H}), 3.99(\mathrm{~s}, 2 \mathrm{H}) .{ }^{13} \mathrm{C} \mathrm{NMR}\left(100 \mathrm{MHz}, \mathrm{CDCl}_{3}, \mathrm{ppm}\right)$ ${ }_{33} \delta: 149.3,142.0,130.2,119.5,110.4,110.0,109.9,104.9,85.9,68.6$, 134 68.2, 68.0, 43.4. HRMS $\left(\mathrm{ES}^{+}\right)$calculated for $\mathrm{C}_{21} \mathrm{H}_{20} \mathrm{~N}_{2} \mathrm{Fe} 356.0976$, 135 found 356.0961

Deposition of bilayer polymeric platform and amperometric detection.-Sequential electrochemical polymerization of the EDOT and $\mathrm{FcPyBz}$ were performed on graphite electrodes by cyclic voltammetry using platinum wire as the counter electrode and the silyer wire as the reference electrode. Graphite rods were hand-polished with an emery paper, washed with distilled water and left to dry at ambient conditions right before the deposition. Firstly, pristine PFcPyBz film was tried to electrochemically coat on the graphite surface however it was observed that there was no homogenous PFcPyBz film coverage. For this reason, EDOT electrochemically polymerized on the graphite surface to have a more convenient platform for $\mathrm{FcPyBz}$ polymerization. Thanks to its electrical conduction characteristics, PEDOT enabled to obtain a very homogenous PFcPyBz film.

$10^{-2} \mathrm{M}$ EDOT solution was prepared in propylene carbonate containing $0.1 \mathrm{M} \mathrm{LiClO}_{4}$, then potentiodynamic coating of PEDOT layer 151 was performed with a repeated scan interval between $-600 \mathrm{mV}$ and $21600 \mathrm{mV}$ with a scan speed of $100 \mathrm{mV} / \mathrm{s}$ in 10 cycles. Then, PE3 DOT coated graphite rods were immersed into propylene carbonate 154 solution containing $10^{-2} \mathrm{M} \mathrm{FCPyBz}$ and $0.1 \mathrm{M} \mathrm{LiClO}_{4}$ for electro155 chemical polymerization by potential cycling between $-600 \mathrm{mV}$ and $1561600 \mathrm{mV}$ for 15 cycles at a scan rate of $100 \mathrm{mV} / \mathrm{s}$. After sequential de157 position of PEDOT and PFcPyBz films on graphite electrode, enzyme immobilization was performed by drop casting of $5 \mu \mathrm{L}$ enzyme so- 158 lution $(1.25 \mathrm{mg}$ of GOx is dissolved in $50 \mathrm{mM}$ phosphate buffer 159 $(\mathrm{pH}=7.0))$ with the help of $5 \mu \mathrm{L} \mathrm{GA}(\% 1)$ and dried thoroughly 160 at room temperature. Dried electrode was rinsed with distilled wa- 161 ter just before the measurement to remove the unbounded species. 162 Construction route for the glucose biosensor is illustrated in Figure 1. 163

All amperometric measurements were carried out at room tem- 164 perature in a reaction cell filled with $10 \mathrm{~mL}$ PBS (phosphate buffered 165 saline, $\mathrm{pH} 7.0$ ) under mild stirring by applying $-0.7 \mathrm{~V}$ constant poten- 166 tial. For consecutive measurements, the electrodes were first washed ${ }_{167}$ with distilled water and then the buffer solution was refreshed. Amper- 168 ometric signals were followed after initial equilibration. The proper 169 amount of substrate was added to the reaction cell. As a result of 170 the enzymatic reaction between GOx and the substrate, the oxygen 171 consumption level associated with the substrate concentration was ex- 172 amined under a constant potential. The difference (under the obtained $\quad 173$ equivalence signal) between before and after the addition of glucose called as the biosensor response and reported as current $(\mu \mathrm{A})$. The 175 proposed sensing system was also tested by determining the glu- 1 cose content in several beverages. The samples were injected into the 177 cell instead of the glucose substrate without any pretreatment. The responses of the biosensor for each sample were recorded and the values were estimated from the calibration curve.

\section{Results and Discussion}

Electrochemical characterization.-Electroactivities of the 182 $\mathrm{PEDOT}, \mathrm{PFcPyBz}$ and $\mathrm{PEDOT} / \mathrm{PFcPyBz}$ films were investigated in 183 $0.1 \mathrm{M} \mathrm{LiCO}_{4}$ solution in propylene carbonate in the range between 184 $-600 \mathrm{mV}$ and $1600 \mathrm{mV}$ at a scan rate of $100 \mathrm{mV} / \mathrm{s}$. The related 185 films were obtained on ITO (indium tin oxide) substrates via cycling 186 the potential for optimum numbers which were determined to obtain 187 the highest current response for the biosensor using same electrolytic ${ }_{18}$ medium and $10^{-2} \mathrm{M}$ of corresponding monomer. As it is shown in the CV spectra of the films in Figure 2, a broad redox couple was obtained for the PEDOT film in a monomer free environment. On the other hand, irreversible oxidation and reduction peaks were obtained for the PFcPvBz film on ITO surface which are located at $1240 \mathrm{mV}$ and $-268 \mathrm{mV}$, respectively. These peaks were also very low in intensity, which shows that it is not possible to obtain a homogenous polymer film on the electrode surface. However, when it was deposited on a PEDOT coated surface (blue curve in Figure 2), a reversible redox couple was obtained for the same monomer concentration and electrolytic medium at $723 \mathrm{mV} / 177 \mathrm{mV}$ for oxidation/reduction. Notably, the trend of the cyclic voltammograms are similar with that trend in surface morphology quality.

Another electrochemical study was carried out in $5.0 \mathrm{mM}$ $\mathrm{Fe}(\mathrm{CN})_{6}{ }^{3-14-}$ solution containing $0.1 \mathrm{M} \mathrm{KCl}$ to investigate the electroactive surface area after depositing the polymer layers and the immobilization of the GOx (Figure 3). Cyclic voltammograms were obtained at a scan rate of $100 \mathrm{mV} / \mathrm{s}$ versus silver wire electrode using platinum wire as the counter. The average values were calculated according to the Randles-Sevcik equation ${ }^{24}$ and found to be $0.313 \mathrm{~cm}^{2}$ for the bare graphite electrode, $0.405 \mathrm{~cm}^{2}$ for the graphite/PEDOT/PFcPyBz and the $0.256 \mathrm{~cm}^{2}$ for the graphite/PEDOT/PFcPyBz/GOx. As it is also discussed in the surface characterization, the porous surface of the deposited polymer layers increases the electrode surface and enhances the electron transfer reactions. The immobilization of an insulating biomolecule on the conducting polymer surface decreases the electroactivity of the corresponding electrode which also indicates an effective attachment of the enzyme to the electrode surface.

Surface characterization.-ATR-FTIR measurements were conducted for PEDOT and PEDOT/PFcPyBz surfaces of the films (Figure 4). Electrochemical depositions of the films were performed by cyclic voltammetry on ITO coated glasses as the working electrodes instead of graphite rods for an easy handling of the samples for the structure characterization. The characteristic peaks of the PEDOT film were observed at $890 \mathrm{~cm}^{-1}, 1027 \mathrm{~cm}^{-1}$ and $1160 \mathrm{~cm}^{-1}$, for the

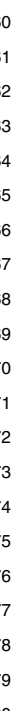
85 87 188 189 190 191 192 193 194 195 196 197 198 199 200 201 202 203 204 205 206 207 208 209 210 211 212 213 214 215 216 


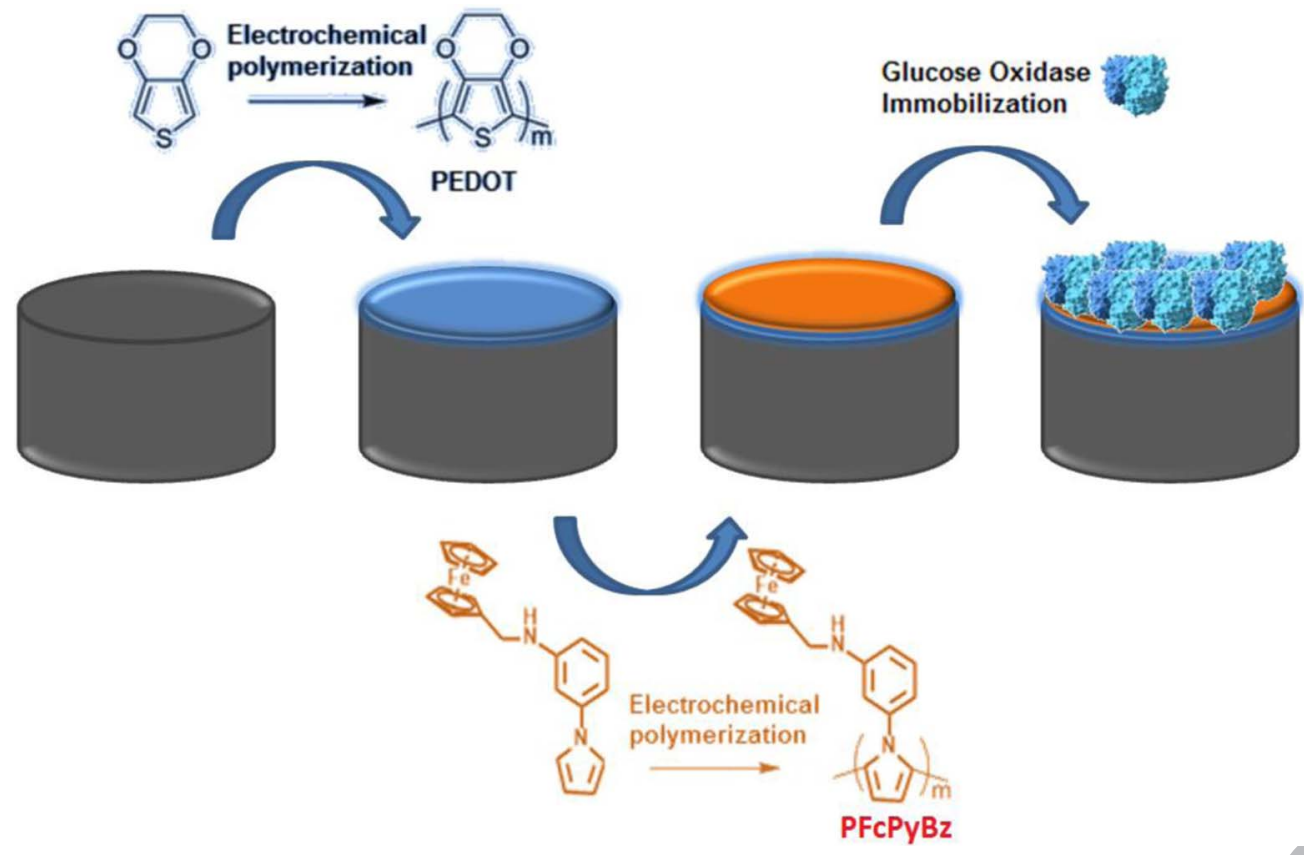

Figure 1. Fabrication of the glucose biosensor used in this work.

$224 \mathrm{C}-\mathrm{S}$, alkylenedioxy and C-O-C stretchings, respectively. ${ }^{25}$ The spec225 trum of PEDOT/PFcPyBz film clearly exhibits the decreased peak 226 intensities of the PEDOT and formation of vibrational bands of pyr227 role and ferrocene rings. The conjugated $\mathrm{C}-\mathrm{N}$ peak was observed 228 at $1174 \mathrm{~cm}^{-1}$ also the $\mathrm{C}-\mathrm{H}$ stretching vibration and $\mathrm{C}-\mathrm{H}$ deforma229 tion peaks are located at $967 \mathrm{~cm}^{-1}$ and $907 \mathrm{~cm}^{-1}$, respectively. ${ }^{26,27}$ 230 Additionally, the band observed at $1402 \mathrm{~cm}^{-1}$ was for the asymmet231 ric stretching vibration of $\mathrm{C}-\mathrm{C}$ bonds of cyclopentadienyl rings of 32 ferrocene. $^{28}$

To correlate the morphology of the modified electrodes with the electrochemistry and the FTIR data, top-view SEM images of the bare graphite electrode, PEDOT coated graphite, PEDOT/PFcPyBz coated graphite and PEDOT/PFcPyBz/GOx immobilized graphite were collected as indicated in Figure 5. Additionally, the SEM image of the $\mathrm{PFcPyBz}$ coated graphite surface without PEDOT layer is also given in Figure 6.

As confirmed by SEM image in Figure 6, a total coating of the bare graphite surface by electrochemical deposition of the PFcPyBz could not be achieved (whereas some partial deposition was observed). On 242 the other hand, a cauliflower like structure with high porosity was 243 monitored from the surface of the PEDOT on graphite (Figure 5b), 244 which is a typical network for conducting polymers. High porosity 245 also means a larger surface area, which was stated in the electro- 246 chemical study in Figure 3. More importantly, an obvious difference 247 was observed between the PEDOT and the PEDOT/PFcPyBz surfaces 248 (Figure 5c), which proves the deposition of PFcPyBz onto PEDOT 249 surface. This result is also in accordance with the results of the CV and 250 ATR-FTIR. From the SEM image of PEDOT/PFcPyBz/GOx surface 251 in Figure 5d, it can be deduced that a successful GOx immobilization 252 was performed with a smooth surface that is related to good anchoring 253 of the biomolecules on the electrode surface.

Optimization studies of the biosensor.-Optimization studies 255 were carried out by following four steps; PEDOT layer thickness 256 optimization on graphite electrode, PFcPyBz layer thickness opti- 257 mization on PEDOT transducer, GOx amount and the $\mathrm{pH}$ value of 258

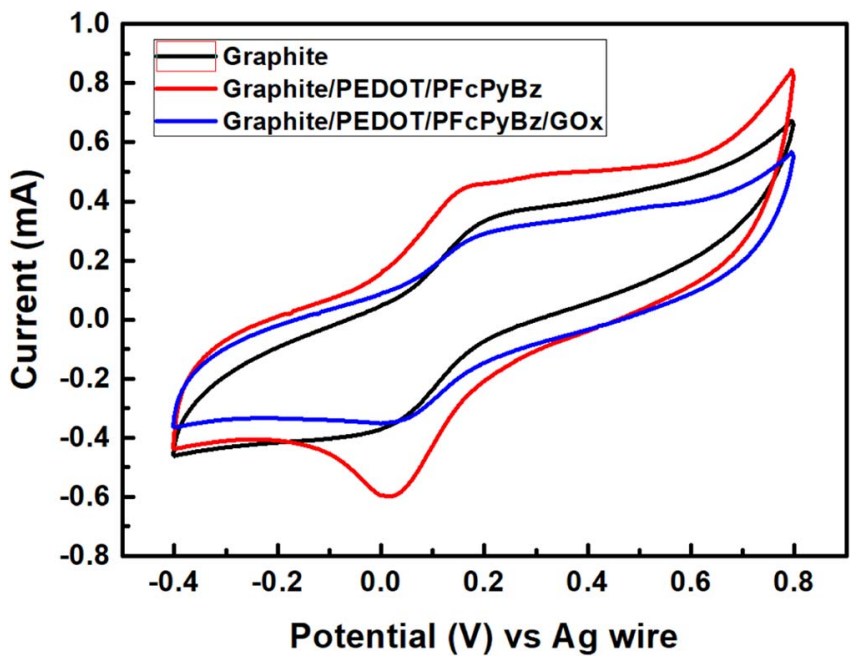

Figure 3. Cyclic voltammograms of the relating surfaces on graphite electrodes in $5.0 \mathrm{mM} \mathrm{Fe}(\mathrm{CN})_{6}{ }^{3-14-}$ containing $0.1 \mathrm{M} \mathrm{KCl}$.
Figure 2. Cyclic voltammograms of the relating polymer surfaces on ITO electrodes obtained in a monomer free environment.

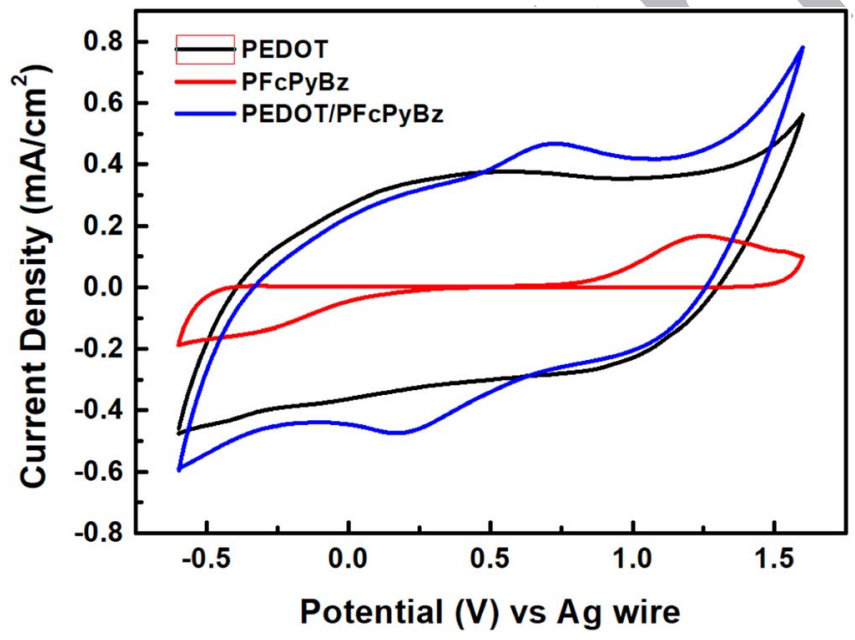




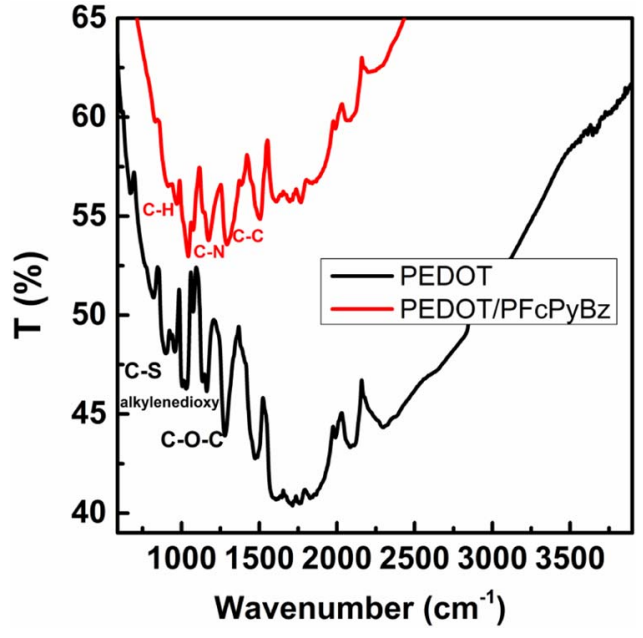

Figure 4. ATR-FTIR spectrum of PEDOT and PEDOT/PFcPyBz before (below) and after (above) PFcPyBz modification.

the buffer solution to obtain the best biosensor performance. Firstly, sequential coatings of the polymers (PEDOT and PFcPyBz) on the graphite electrode were optimized to have a smooth and electronically active surface for the enzyme immobilization. The thickness of the polymer films on the graphite surface is very crucial in terms of an efficient biosensor response. The ferrocene containing polymer $(\mathrm{PFcPyBz})$ serves as an electron transfer mediator between the redox center of the GOx and the electrode surface. Therefore, the number of the ferrocene units is yet another deciding factor in the amperometric response of the corresponding sensor. For an efficient biosensor, polymer layer thicknesses were optimized accordingly. Firstly, EDOT monomer $\left(10^{-2} \mathrm{M}\right)$ was dissolved in propylene carbonate $(\mathrm{PC})$ containing $0.1 \mathrm{M} \mathrm{LiClO}_{4}$ and deposited on different graphite working electrodes with varying scan numbers between 5 and $20(5,10,15$ and $20)$. The scan number of the second polymeric layer was kept constant as 10 cycles. Comparing the current responses with the scan numbers of the PEDOT layers, the highest response was obtained from the 10 cycles of PEDOT layer deposition and it was decided as the optimum number for the following optimization steps (Figure 7a). The second
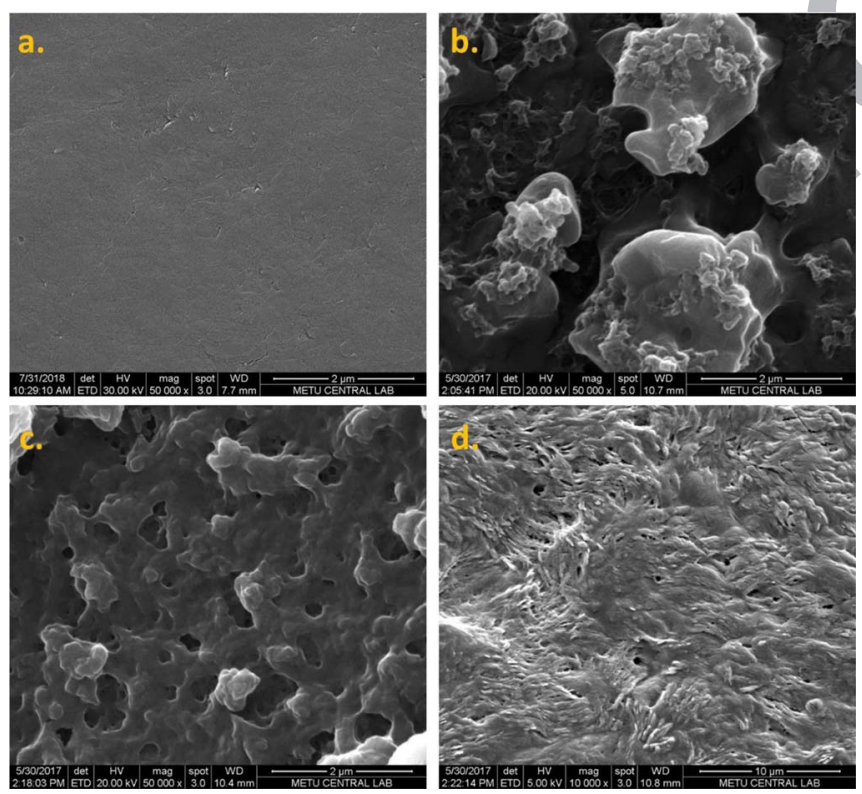

Figure 5. SEM images of (a) bare graphite electrode, (b) PEDOT layer, (c) PEDOT/PFcPyBz layers and (d) PEDOT/PFcPyBz/GOx on graphite surface.
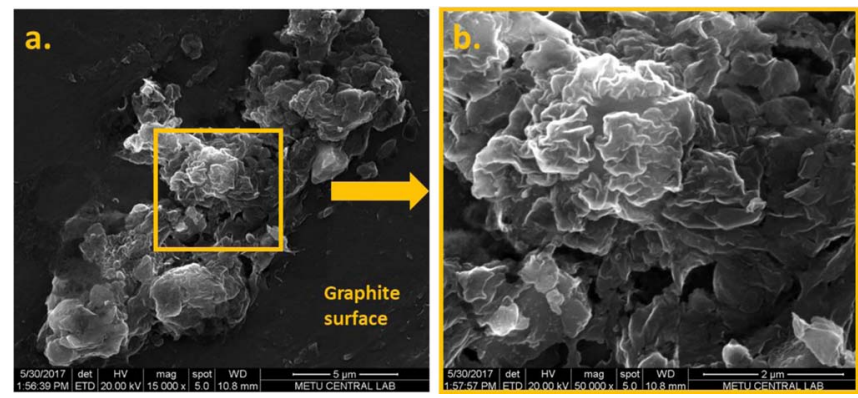

Figure 6. SEM images of $\mathrm{PFcPyBz}$ on bare graphite surface with different magnifications a) 15000x and b) 50000x.

optimization was performed for the $\mathrm{PFcPyBz}$ using the same elec- 278 trolytic medium used for the EDOT polymerization. The $10^{-2} \mathrm{mmol} 279$ of $\mathrm{FcPyBz}$ monomer was dissolved in a $1 \mathrm{~mL}$ of PC solution contain- 280 ing $0.1 \mathrm{M} \mathrm{LiClO}_{4}$ and the electrochemical deposition was performed 281 onto four different PEDOT coated graphite electrodes using 5, 10, 15282 and 20 scan numbers. The highest response was obtained from the 15283 cycles of polymerization of the FcPyBz and chosen as the optimum 284 condition (Figure 7b). Without optimizing the thickness range for the 285 sensor system, diffusion problems between the polymer coated elec- 286 trode and the biomolecule, or denaturation of biomolecules may arise. 287 As shown in Figures 7a and 7b, the highest response for biosensor 288 application was recorded with 10 cycles of PEDOT film and 15 cycles 289 of PEDOT/PFcPyBz film deposition, which corresponds to $120 \mathrm{~nm} 290$ (the equivalent of a $54 \mathrm{mC}$ charge).

For the third optimization step, five different amounts of GOx (GOx; $0.5 \mathrm{mg}, 0.75 \mathrm{mg}, 1.0 \mathrm{mg}, 1.25 \mathrm{mg}$ and $1.50 \mathrm{mg}$ ) were dissolved in the same buffer solution and immobilized on the optimized polymer surface with glutaraldehyde (1\%). The biosensor response increased with increasing enzyme amount and reached a maximum for $1.25 \mathrm{mg}$ of GOx for the same amount of substrate. However, the current value decreases when the enzyme amount increased to $1.50 \mathrm{mg}$, which means that the higher enzyme concentration hinders the electron transfer. Additionally, excess loading of enzyme resulted in leaching from the surface since the enzyme molecules on the surface were not sufficiently stable (Figure 7c). On the contrary, inadequate enzyme loading caused low sensitivity of the biosensor. As the final step, the optimization of the $\mathrm{pH}$ value of the buffer solution was performed preparing different buffer solutions having the $\mathrm{pH}$ values as 5.5, 6.0, 6.5, 7.0, 7.5 and 8.0. It is known that the GOx is an active enzyme in the range of $\mathrm{pH} 3.0$ and $\mathrm{pH} 8.0 .^{29}$ According to the current response of the sensors in different $\mathrm{pH}$ mediums, $\mathrm{pH}$ 7.0 PBS buffer was determined as the optimum solution medium and used for the further analyses (Figure 7d).

Analytical characterization.-The classical amperometric curve of the biosensor is recorded by successively adding different concentrations of glucose at a constant potential. A linearity (inset figure of Figure $8 \mathrm{a}$ ) was obtained in the range $0.01-0.50 \mathrm{mM}$ of glucose concentration with an equation of $y=7.5905 x+0.0901\left(R^{2}=0.997\right)$. Obtained calibration curve was used to calculate the other analytical parameters of the biosensor. The limit of detection (LOD) was calculated as $54 \mu \mathrm{M}$ according to the concept of signal-to-noise ratio $(\mathrm{S} / \mathrm{N}=3)$. The sensitivity of the biosensor and $\mathrm{K}_{\mathrm{M}}{ }^{\text {app }}$ value (Michaelis-Menten constant) were determined as $112.2 \mu \mathrm{A} / \mathrm{mMcm}^{2}$ and $0.05 \mathrm{mM}$, respectively. Apparent Michealis-Menten constant, $\mathrm{K}_{\mathrm{M}}$ app value was obtained from Lineweaver-Burk plot. High sensitivity and such a low $\mathrm{K}_{\mathrm{M}}{ }^{\text {app }}$ value perform high affinity toward the glucose. It shows that the $\mathrm{K}_{\mathrm{M}}$ app is very good compared to that of other studies. For example, a glucose biosensor prepared using a nafion and nano scaled cobalt phthalocyanine (NanoCoPc) film gives a $\mathrm{K}_{\mathrm{M}}{ }^{\text {app }}$ value of $12.4 \mathrm{mM} .^{30} \mathrm{In}$ another example, based on a CoPc-CoTPP complexes and Nafion film, it was calculated to be $14.91 \mathrm{mM}^{31}$ Moreover, In 2013, Wang constructed a glucose biosensor containing branched polyethyleneimine (1) 0 2 83 4 85 86 8 9 290 291 292 293 294 295 296 297 298 299 300 301 302 303 304 305 306 307 308 309 310 
a.

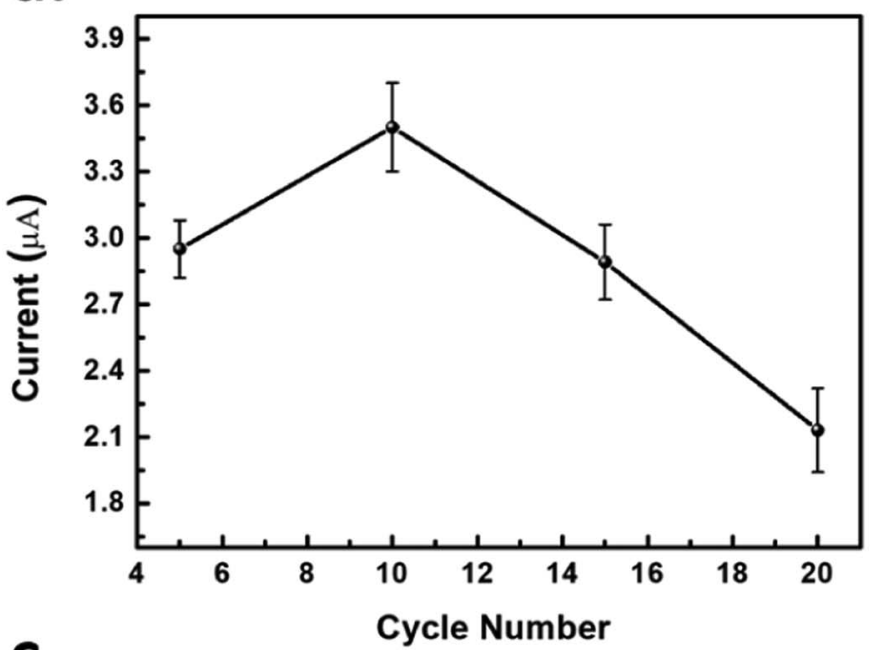

C.

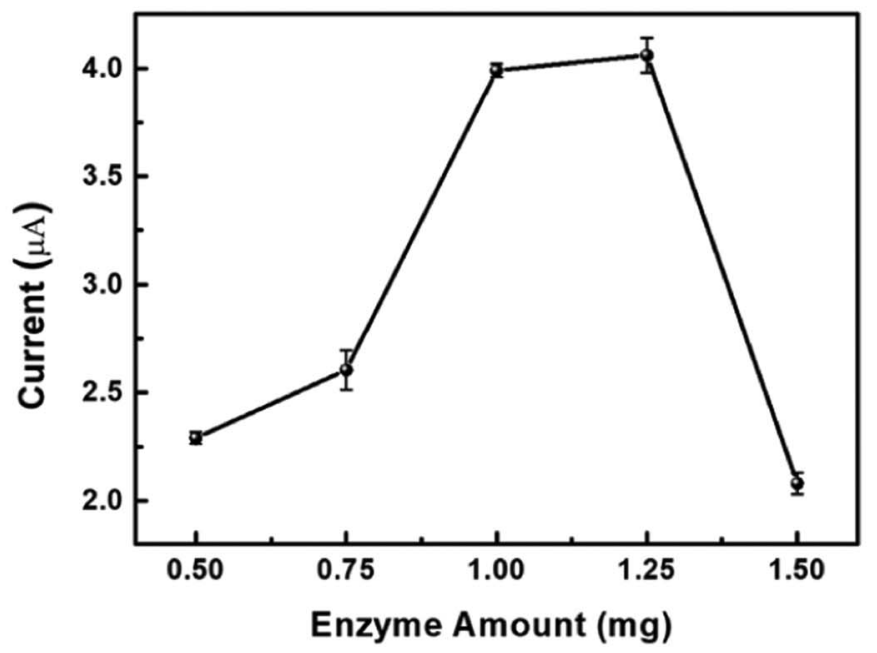

b.

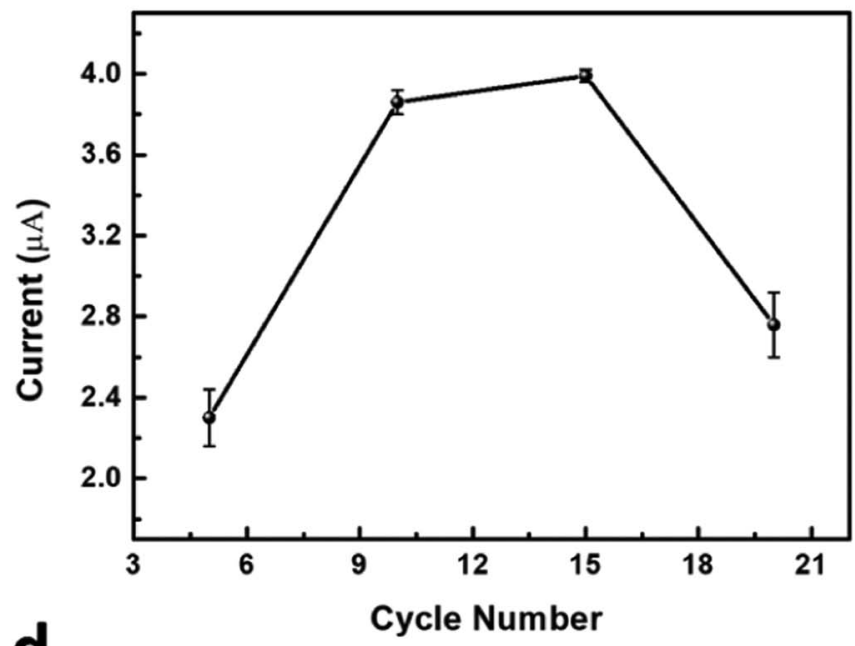

d.

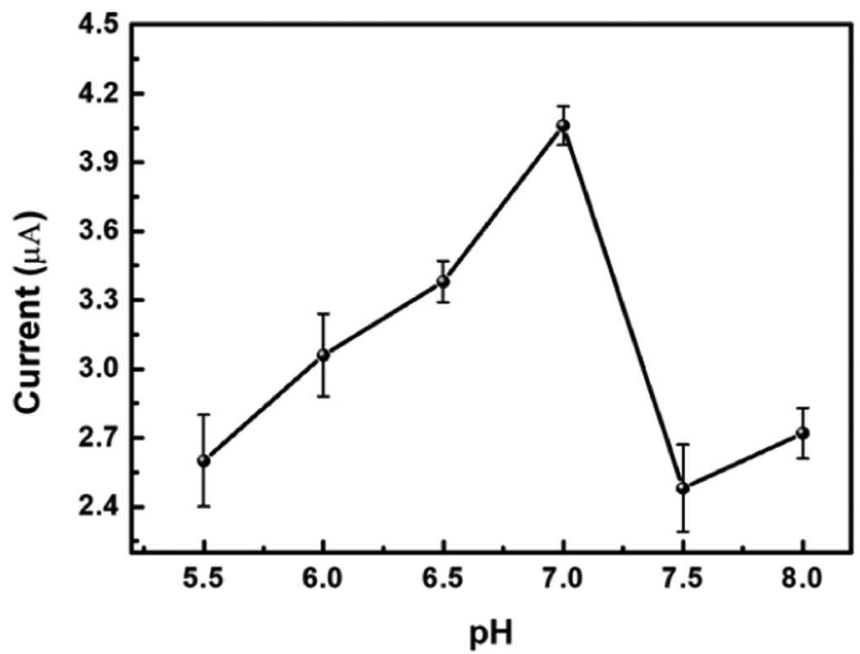

Figure 7. The effect of the cycle number of the PEDOT (a) and PFcPyBz (b), enzyme amount (c) and pH value (d) on the biosensor performance. Error bars show the standard deviation (SD) of three measurements.
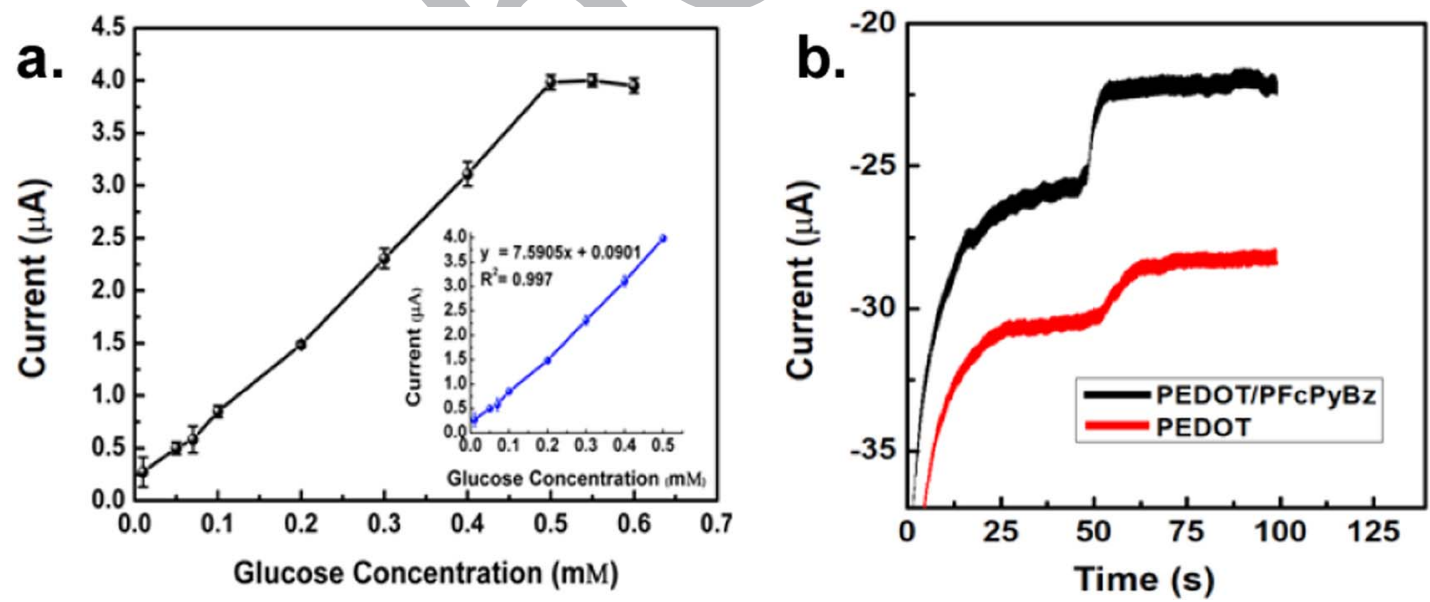

Figure 8. a) Calibration curve for glucose concentration in $50 \mathrm{mM}$ PBS, $\mathrm{pH} 7.0,-0.7 \mathrm{~V}$ ). Error bars show the SD of three measurements (Linear range as an inset.) b) Comparison of the current responses of PEDOT/PFcPyBz and PEDOT surfaces for $0.5 \mathrm{mM}$ glucose. 
Table I. List of the glucose biosensor based on conjugated polymers.

\begin{tabular}{|c|c|c|c|c|c|}
\hline Electrode matrix & Sensitivity $\left(\mu \mathrm{A} \mathrm{cm}^{-2} \mathrm{mM}^{-1}\right)$ & $\mathrm{K}_{\mathrm{M}}{ }^{\text {app }}(\mathrm{mM})$ & $\operatorname{LOD}(\mu \mathrm{M})$ & Linear Range (mM) & Reference \\
\hline BPEI-Fc/PEDOT:PSS/GOx & 66 & 2.4 & NR & $0.5-4.5$ & 32 \\
\hline Poly(BEDOA-6)/AuNPs/MPA & 14.97 & 0.81 & 25 & $0.025-1.25$ & 33 \\
\hline $\mathrm{Py} 0.2 / \mathrm{PyCO} 2 \mathrm{H} 0.2 / \mathrm{PyFc} 0.6$ & 1.796 & 4.73 & 6.9 & $1.0-4.0$ & 34 \\
\hline BNNTs-Pani-Pt-GOD & 19.02 & 3.4 & 0.18 & $0.01-5.5$ & 35 \\
\hline PDDA/PSS/\{PDDA-MWCNTs/GOx $\} 5$ & 5.60 & NR & 58 & Up to 5.0 & 36 \\
\hline PEDOT/PFcPyBz/GOx & 112.2 & 0.05 & 54 & $0.01-0.5$ & This work \\
\hline
\end{tabular}

330 binding with ferrocene having a sensitivity value of $66 \mu \mathrm{A} \mathrm{cm}^{-2}$ ${ }_{331} \mathrm{mM}^{-1}$ and $2.4 \mathrm{mM} \mathrm{K}_{\mathrm{M}}{ }^{\text {app }}$ value. ${ }^{32}$ In the same year, a similar type 332 of glucose biosensor showed a very low $\mathrm{K}_{\mathrm{M}}$ app value $(0.81 \mathrm{mM})$ by 333 modification of gold nanoparticles of the electrode matrix. ${ }^{33}$ Senel 334 and coworkers also developed another glucose biosensor containing 335 pyrrole and ferrocene moieties and sensitivity and $\mathrm{K}_{\mathrm{M}}{ }^{\text {app }}$ values were 336 estimated as $1.796 \mu \mathrm{Acm}^{-2} \mathrm{mM}^{-1}$ and $4.73 \mathrm{mM}$, respectively. ${ }^{34}$ Other 337 references cited in Table I, also describes a similar glucose sensor ap38 plication with similar sensor performances.

339 Electroanalytical performance of the corresponding biosensor was 340 tested by addition of required amount of glucose into $10 \mathrm{~mL} 50 \mathrm{mM}$ 341 PBS buffer medium under applied potential of $-0.7 \mathrm{~V}$. Before a 342 detailed analytical characterization of the proposed biosensor (PE${ }_{343} \mathrm{DOT} / \mathrm{PFcPyBz} / \mathrm{GOx}$ ), the biosensor without the PFcPyBz layer (PE344 DOT/GOx) was also constructed and the current responses were com345 pared. As shown in Figure 8b, The PEDOT/PFcPyBz/GOx gives a 346 higher response toward glucose than the PEDOT/GOx modified one. 347 Through the use of PFcPyBz layer, the sensing response of the biosen348 sor was increased by as much as two folds.

349 To examine the repeatability of the biosensor responses, signals 350 corresponding to $0.5 \mathrm{mM}$ glucose standard solutions were measured 351 for seven times using the same sensor. The standard deviation (S.D) 352 and relative standard deviation (RSD) values were calculated as 0.051 353 and $1.29 \%$, respectively. The signals were recorded under the same 354 experimental conditions. According to the data, it can be said that $355 \mathrm{PEDOT} / \mathrm{PFcPyBz} / \mathrm{GOx}$ based glucose biosensor is capable to gener356 ate a reproducible output while performing series of measurements. 357 Moreover, as for reproducibility of the devices, three independent sen358 sors were prepared by measuring of the current responses to $0.5 \mathrm{mM}$ 359 glucose at the optimized working conditions. The results showed that 360 all devices showed almost the same properties after each preparation 361 and $1.13 \%$ relative standard derivation (RSD) was obtained. Preci362 sion of the PEDOT/PFcPyBz/GOx electrode was also evaluated by 363 assaying one enzyme electrode for three replicated determinations in $3640.5 \mathrm{mM}$ glucose and its responses were compared with the ones for 365 beverages. As shown in Table II, results are very close to the prod66 uct label values proving that the fabricated biosensor is feasible for practical sample testing with reliable accuracy and precision.

Interference study was also performed for the proposed biosensor (Figure 9A). Ascorbic acid and urea were used as the interfering agents to observe the affinity of the PEDOT/PFcPyBz/GOx sensor to these materials. Ascorbic acid and urea solutions were tested repeatedly in 2 the same system. Only a slight negative biosensor signal has been observed after the injection of ascorbic acid while the injection of 374 the same concentration of urea into the reaction cell did not alter 375 the electrochemical response of the biosensor at all. When a slight 376 negative biosensor signal of the ascorbic acid was compared with

Table II. Amperometric results of glucose levels using $\mathrm{PEDOT} / \mathrm{PFCPyBz} / \mathrm{GOx}$ biosensor in various beverages.

\begin{tabular}{lccc}
\multicolumn{1}{c}{ Sample } & $\begin{array}{c}\text { Product } \\
\text { Label }(\mathrm{mM})\end{array}$ & $\begin{array}{c}\text { Biosensor } \\
\text { Response }(\mathrm{mM})\end{array}$ & $\begin{array}{c}\text { Relative } \\
\text { Error }(\%)\end{array}$ \\
\hline L ice tea peach & 0.383 & 0.373 & 2.61 \\
U lemonade & 0.389 & 0.374 & 3.95 \\
S milk & 0.125 & 0.121 & 3.20
\end{tabular}

the huge signal of the proposed sensor, it is negligible. Moreover, the 377 selectivity of the biosensor toward the substrate was tested by injecting 378 different sugars. As seen in Figure 9B, no signal was detected after 379 the injection of $0.5 \mathrm{mM}$ of galactose, mannose, fructose, sucrose and 380 Xylose. This shows that the biosensor exhibits excellent selectivity 381 and performs well in the presence of different compounds.

Sample application.-Various beverages were used to evaluate the 383 reliability of the corresponding biosensor under optimized conditions. 384 $\mathrm{PEDOT} / \mathrm{PFcPyBz} / \mathrm{GOx}$ biosensor was used to determine the glucose 385 level of an ice tea, lemonade and milk samples without further dilution. 386 Amperometric responses were calculated using the linearity equation 387 and compared with the reference values. As seen from Table II, it 388
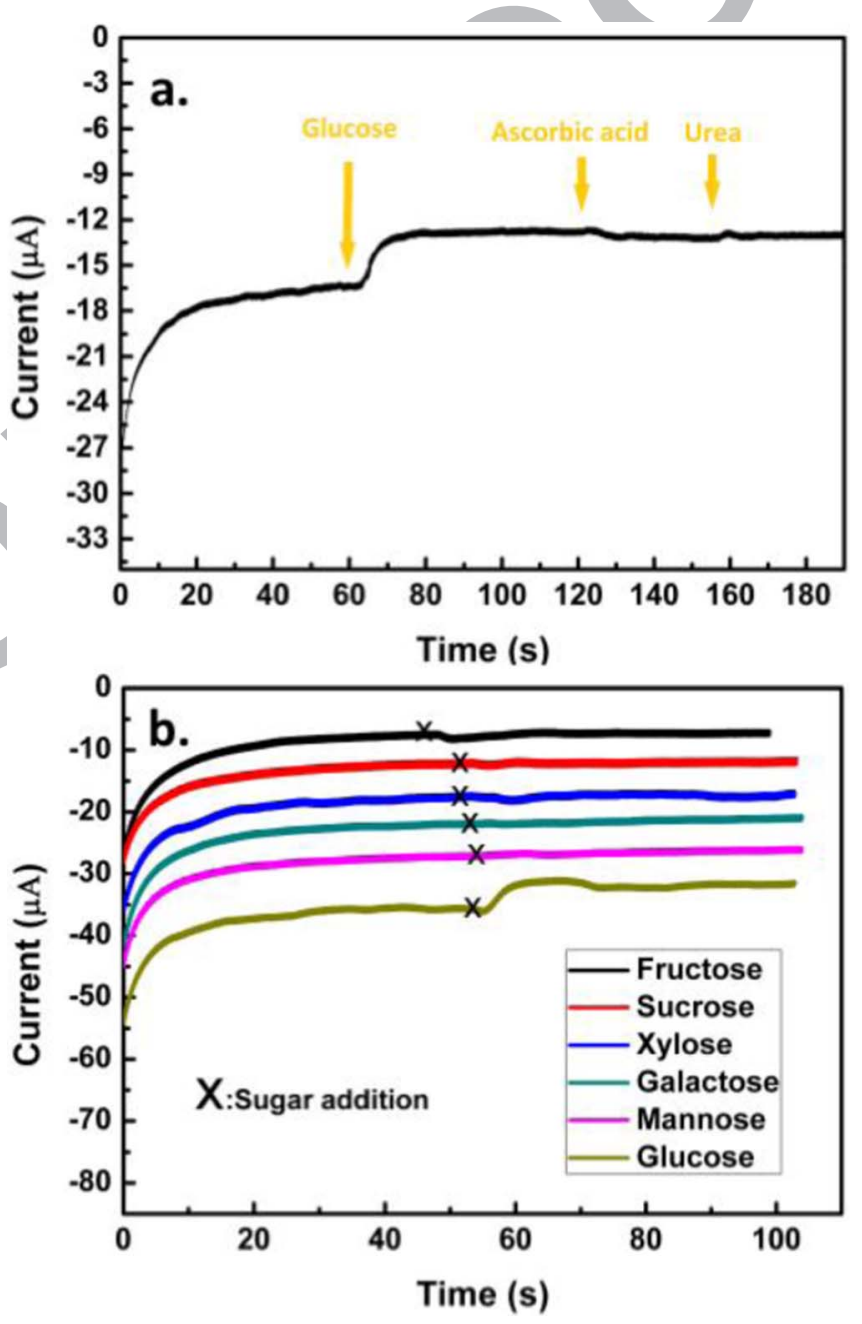

Figure 9. a) Amperometric responses of PEDOT/PFcPyBz/GOx biosensor to glucose and interference studies with ascorbic acid and urea, b) the selectivity of the biosensor toward the different sugars. 
389 is possible to detect the glucose level of commercial products even

391

392

393

394 390 having different ingredients with a very low error.

395 of FcPyBz monomer. With this aspect, a novel polymeric platform was

396 designed and successfully constructed for glucose biosensor applica-

397 tion. From the electrochemical analyses it was observed that PEDOT

398 modification of an electrode surface improves the electrochemical

399 deposition of a molecule having steric hindrance. According to the

400 analytical characterization, preparation of the polymeric platform has

401 the main effect on biosensor performance. High sensitivity and low

$402 \mathrm{~K}_{\mathrm{M}}$ app values show that constructed biosensor has a high affinity to the

403 glucose substrate selectively and it is possible to detect the glucose

404 amount in commercial beverages with very small relative error values.

\section{ORCID}

Hava Zekiye Kaya (1D https://orcid.org/0000-0002-5844-3459

\section{References}

8. M. Z. Cetin and P. Camurlu, J. Electrochem. Soc, 164(12), B585 (2017).

9. T. C. Gokoglan, M. Kesik, S. Soylemez, R. Yuksel, H. E. Unalan, and L. Toppare, J. Electrochem. Soc., 164(6), G59 (2017).

10. C.-W. Hsu, W.-C. Feng, F.-C. Su, and G.-J. Wang, J. Electrochem. Soc., 162(10), B264 (2015).

11. S. Kakhki, M. M. Barsan, E. Shams, and C. M. A. Brett, Electroanal., 25, 77 (2013).

12. X. Xiao, M. Wang, H. Li, and P. Si, Talanta, 116, 1054 (2013).

13. P.-C. Nien, T.-S. Tung, and K.-C. Ho, Electroanal., 18(13-14), 1408 (2006).

14. X. Zhai, K. Li, F. Guan, N. Wang, M. Agievich, J. Duan, and B. Hou, Surf. Coat. Tech., 356, 19 (2018).

15. E. Cevik, M. Titiz, and M. Senel, Electrochim. Acta, 291, 41 (2018).

16. T. J. Kealy and P. L. Pauson, Nature, 168, 1039 (1951).

17. S. A. Miller, J. A. Tebboth, and J. F. Tremaine, J. Chem. Soc., 632 (1952)

18. N. Palomera, J. L. Vera, E. Meléndez, J. E. Ramirez-Vick, M. S. Tomar, S. K. Arya, and S. P. Singh, J. Electroanal. Chem., 658, 33 (2011).

19. R. Ayranci, D. O. Demirkol, M. Ak, and S. Timur, Sensors, 15, 1389 (2015).

20. T. Soganci, D. O. Demirkol, M. Ak, and S. Timur, RSC Adv., 4, 46357 (2014).

21. H. Dzudzevic, S. Soylemez, Y. Akpinar, M. Kesik, S. Goker, G. Gunbas, M. Volkan, and L. Toppare, ACS Appl. Mat. Int., 8(12), 8058 (2016).

22. C. Bicak, M. Gicevicius, C. Gökoğlan, G. Yilmaz, A. Mindaugas, L. Toppare, and Y. Yagci, Macromolecules, 50, 1824 (2017).

23. G. Galley, A. Goergler, K. Groebke Zbinden, R. Norcross, and H. Stalder, PCT Int. Appl., WO 2008046757 A1 20080424 (2008).

24. A. J. Bard and L. R. Faulkner, Electrochemical methods: Fundamentals and applications, New York: John Wiley, (2000).

25. B. Wei, L. Ouyang, J. Liu, and D. C. Martin, J. Mater. Chem. B, 3, 5028 (2015).

26. B.-Y. Yang, Y. Cao, F.-F. Qi, X.-Q. Li, and Q. Xu, Nanoscale Res. Lett., 10, 207 (2015).

27. Q. Xu, S. Y. Wu, M. Wang, X. Y. Yin, Z. Y. Wen, and W. N. Ge, Chromatographia., 71(5-6), 487 (2010)

28. T. Ghosh, P. Sarkar, and A. P. F. Turner, Bioelectrochemistry, 102, 1 (2015)

29. H. J. Brights and M. Appleby, J. Biol. Chem., 244, 3625 (1969).

30. K. W. Jing, J. Xu, and H. Y. Chen, Biosens. Bioelectron., 20(7), 1388 (2005).

31. K. I. Ozoemena and T. Nyokong, Electrochim. Acta, 51, 5131 (2006).

32. J.-Y. Wang, L.-C. Chen, and K.-C. Ho, ACS Appl. Mater. Interfaces, 5, 7852 (2013).

33. M. Kesik, F. E. Kanik, G. Hizalan, D. Kozanoglu, E. N. Esenturk, S. Timur, and L. Toppare, Polymer, 54, 4463 (2013).

34. M. Senel, Synthetic Met., 161, 1861 (2011).

35. J. Wu and L. Yin, ACS Appl. Mater. Interfaces., 3, 4354 (2011).

36. H. T. Zhao and H. X. Ju, Anal. Biochem., 350, 138 (2006).
416 (2012).

7. A. Valiūnienè, P. Virbickas, A. Rekertaite, and A. Ramanavičius, J. Electrochem. Soc 164(14), B781 (2017).

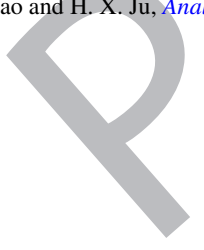




\section{Query}

Q1: AU: Please provide a digital object identifier (doi) for Ref(s) 23 and 29. For additional information on doi's please select this link: http://www.doi.org/. If a doi is not available, no other information is needed from you. 